\title{
Desmosine as a biomarker of elastin degradation in COPD: current status and
} \section{future directions}

\author{
M. Luisetti, S. Ma, P. ladarola, P.J. Stone, S. Viglio, B. Casado, Y.Y. Lin, \\ G.L. Snider and G.M. Turino
}

ABSTRACT: Desmosine (DES) and isodesmosine (IDES) are two unusual, tetrafunctional, pyridinium ring-containing amino acids involved in elastin cross-linking. Being amino acids unique to mature, cross-linked elastin, they are useful for discriminating peptides derived from elastin breakdown from precursor elastin peptides. According to these features, DES and IDES have been extensively discussed as potentially attractive indicators of elevated lung elastic fibre turnover and markers of the effectiveness of agents with the potential to reduce elastin breakdown. In the present manuscript, immunology-based and separation methods for the evaluation of DES and IDES are discussed, along with studies reporting increased levels of urine excretion in chronic obstructive pulmonary disease (COPD) patients with and without $\alpha_{1}$ antitrypsin deficiency. The results of the application of DES and IDES as surrogate end-points in early clinical trials in COPD are also reported. Finally, recent advances in detection techniques, including liquid chromatography tandem mass spectrometry and high-performance capillary electrophoresis with laser-induced fluorescence, are discussed. These techniques allow detection of DES and IDES at very low concentration in body fluids other than urine, such as plasma or sputum, and will help the understanding of whether DES and IDES are potentially useful in monitoring therapeutic intervention in COPD.

KEYWORDS: Body fluids, capillary electrophoresis, elastin peptides, HPLC, laser-induced fluorescence, mass spectrometry

hronic obstructive pulmonary disease (COPD) is characterised by an increasing worldwide prevalence. The World Health Organization predicts that by 2020 this disorder will rank as the fifth most prevalent disease and the third most common cause of death [1, 2]. Reasons for the increase include social, economic and environmental issues. Also, COPD research has been slow to evolve effective therapies [3]; as a result, the major therapeutic approach in reducing COPD progression is smoking cessation [4].

A continuing problem in the development of therapies for COPD is that COPD develops over many years. Short-term evaluation of disease progression is therefore difficult, owing to a lack of sensitive parameters of lung injury and destruction. A workshop was held in Tyler (TX,
USA) 18 yrs ago, to analyse existing information and to develop plans that could lead to the clinical testing of medications directed at the underlying cause of COPD in smokers [5]. Surrogate end-points (i.e. effective substitutes for the clinical outcome) of lung destruction were grouped into three categories: 1) measurements of physiological lung function; 2) computed tomography (CT) analysis of lung parenchyma; and 3) biochemical or immunological measurements of extracellular matrix degradation or elastase activity [6]. Desmosine (DES), a crosslink unique to mature elastin, has been extensively discussed as a potentially attractive indicator of elevated lung elastic fibre turnover and a marker of the effectiveness of agents with the potential to reduce elastin breakdown. The

Earn CME accreditation by answering questions about this article. You will find these at the back of the printed copy of this issue or online at www.erj.ersjournals.com/current.shtml

AFFILIATIONS

For affiliations, please see the Acknowledgements section.

\section{CORRESPONDENCE}

M. Luisetti, Laboratorio di Biochimica e Genetica, Clinica di Malattie dell'Apparato Respiratorio,

Fondazione IRCCS Policlinico San Matteo, Università di Pavia, Piazza Golgi 19, 27100 Pavia, Italy. Fax: 390382422267

E-mail: m.luisetti@smatteo.pv.it

Received:

December 232007

Accepted after revision:

June 082008

SUPPORT STATEMENT

This work was supported by funds from the James P. Mara Center for Lung Disease (New York, NY, USA), the Flight Attendants Medical Research Institute (Miami, FL, USA), the Charles A. Mastronardi

Foundation (Wilmington, DE, USA), the Ned Doyle Foundation (New York) and the Alpha One Foundation (Miami), and also by funds from Ethel Kennedy, John Kennedy and Judith Sulzberger (New York), by an unrestricted grant from the AlphaOne International Registry (Leiden, the Netherlands), by the Fondazione IRCCS Policlinico San Matteo (Pavia, Italy) and by the Fondazione Cariplo (Milan, Italy)

\section{STATEMENT OF INTEREST}

None declared. 
a)<smiles>NC(CCc1c[n+](CC(N)C(=O)O)cc(CC(N)C(=O)O)c1CC(N)C(=O)O)C(=O)O</smiles>

b)<smiles>NC(CCc1cc(CC(N)C(=O)O)c[n+](CC(N)C(=O)O)c1CCC(N)C(=O)O)C(=O)O</smiles>

FIGURE 1. Schematic structures of a) desmosine and b) isodesmosine.

present manuscript aims to evaluate the evidence achieved in the last 18 yrs on how measurements of DES and, more recently, of its companion cross-link, isodesmosine (IDES), provide significant parameters for the onset, progression and therapeutic responses in COPD.

\section{ELASTIN BREAKDOWN PRODUCTS AND METHODS OF MEASUREMENT}

Mature elastic fibres are composed of insoluble elastin deposited on a scaffold composed of microfibrils. Insoluble elastin derives from cross-linking tropoelastin, a soluble 75-kD biosynthetic precursor [7]. The cross-linking of tropoelastin occurs in the extracellular space between lysines in the hydrophilic regions, the process being catalysed by the copper-requiring enzyme lysyl oxidase. Two unusual, tetrafunctional, pyridinium ring-containing amino acids are involved in elastin cross-linking, DES and IDES (fig. 1) [8].

Plasma normally contains fragments derived from tropoelastin and from degraded cross-linked mature elastin. It has been reported that these circulating fragments cover a wide variety of sizes, peaking at $70 \mathrm{kD}$, but with a significant proportion of those with lower molecular weight (MW) than expected [9]. The latter are normally excreted in urine. Chromatographic separation of elastin fragments in human urine has detected polypeptides over a wide range of $\mathrm{MW}$, from $<5 \mathrm{kD}$ to $>50 \mathrm{kD}$, peaking at 10-50 kD [9]. ELISAs have been developed in the past for quantification of these fragments in body fluids $[9,10]$. Although these methods may have several advantages, including simplicity and lack of interference by plasma proteins, the assay is unable to discriminate between normal and COPD

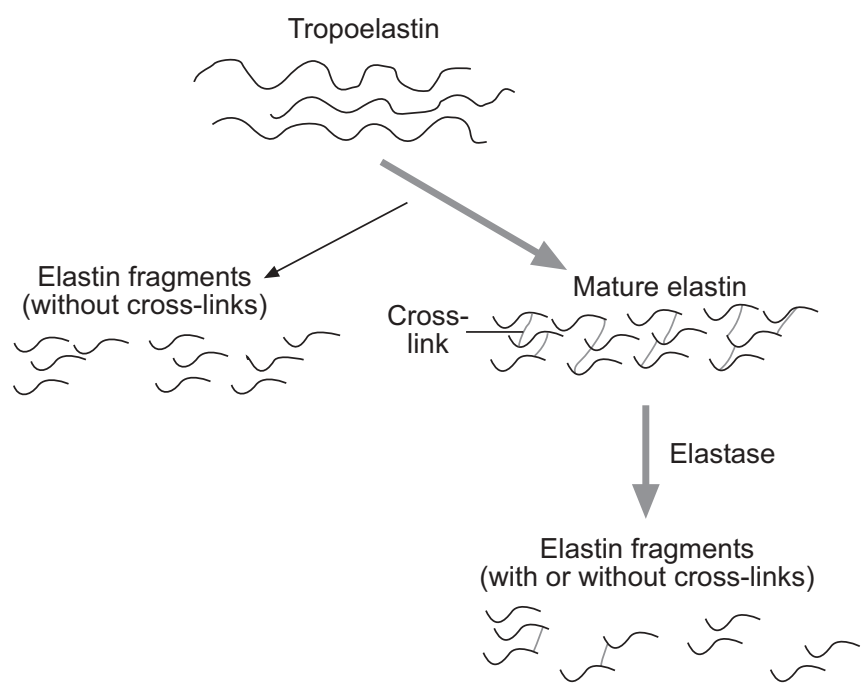

FIGURE 2. Pathway of elastin-derived fragment (EF) formation. EFs containing desmosine derive only from the degradation of mature, cross-linked elastin; EFs not containing desmosine may derive either from tropoelastin during assembly of mature elastin or from degradation of mature, cross-linked elastin.

subjects, or to chemically characterise the immunoreactive material (i.e. unable to discriminate precursor elastin peptides from those of mature elastin) [6].

This problem can be circumvented by methods that recognise DES, which is unique to cross-linked elastin (fig. 2). Immunology-based methods for DES detection in urine include ELISA [11] and radioimmunoassay (RIA) [12, 13]. The latter method has undergone progressive modifications, after which urine did not require acid hydrolysis [14], and the specificity improved [6]. The method is cheap and rapid.

A different strategy lies in chromatographic isolation of DES from urine and its subsequent quantification. STONE et al. [15] developed a method based on isotope dilution and HPLC. The method is labour intensive and requires preliminary urine hydrolysis, but it is very accurate, since an internal correction for material losses is provided by addition and recovery of labelled tracer amounts of DES. Normal urine levels of DES determined by HPLC are three- to four-fold lower than those determined by RIA, thus suggesting that RIA might measure high background levels of contaminants cross-reacting with the antibody [16]. An alternative, more recently reported method is the separation of urinary DES by high-performance capillary electrophoresis (HPCE) in its micellar electrokinetic chromatography modality [17]. This technique has the advantages of being more rapid, automated and less expensive than other procedures. However, lack of an internal standard precludes corrections for losses. Normal urinary DES levels determined by HPCE (mean \pm SD $9.3 \pm 2.7 \mu$ g per g creatinine) [18] are approximately of the same order of magnitude as those obtained by HPLC $(7.5 \pm 1.4 \mu \mathrm{g}$ per $\mathrm{g}$ creatinine). Further improvement in the analysis was reported by the use of combined HPLC and liquid chromatography mass spectrometry (LC-MS) analysis [19], in which both DES and IDES can be determined separately with higher sensitivity and specificity. DES and IDES levels in normal urine $(n=7)$ obtained by the LC-MS analysis are $8.67 \pm 3.75$ and $6.28 \pm 2.87 \mu \mathrm{g}$ per $\mathrm{g}$ creatinine, respectively. A review article containing detailed 
TABLE 1 Procedures applied to detect desmosines in real samples

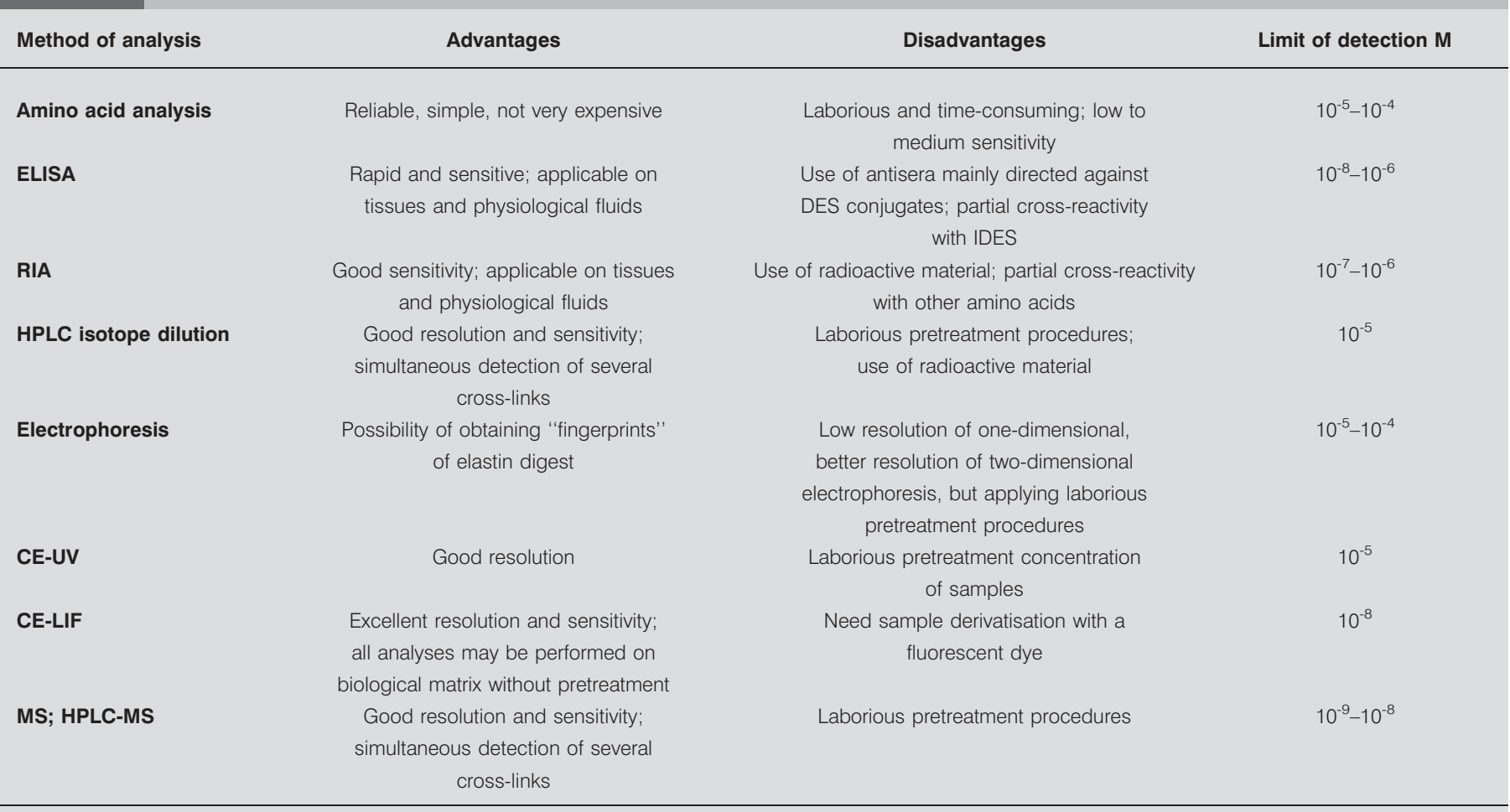

RIA: radioimmunoassay; CE: capillary electrophoresis; UV: ultraviolet; LIF: laser-induced fluorescence; MS: mass spectrometry; DES: desmosine; IDES: isodesmosine.

information about the different procedures so far applied to the determination of desmosines in different biological matrices has been recently published [20]; the procedures are also summarised in table 1.

\section{URINARY DES LEVELS IN NORMAL NONSMOKING OR SMOKING INDIVIDUALS AND IN COPD PATIENTS WITH OR WITHOUT $\alpha_{1}$-ANTITRYPSIN DEFICIENCY}

The hypothesis that destruction of lung elastin, which occurs in pulmonary emphysema, may be associated with increased urinary excretion of DES was corroborated by animal models of lung injury induced by intratracheal injection of proteolytic enzymes. GOLDSTEIN and STARCHER [21] have demonstrated that acute loss of elastin and emphysema occurred in hamsters after intratracheal injection of a single dose of pancreatic elastase. This was associated with urinary excretion of DES representing $61 \%$ of the elastin lost from the lungs. Subsequently, this result was confirmed by JANOFF et al. [22] in sheep and by STONE et al. [15] in the hamster after injection of pancreatic or neutrophil elastase. Both studies showed a positive correlation between urinary DES excretion and airspace enlargement in these animal models of pulmonary emphysema.

The first reports in human beings (both obtained by an RIA detection technique) gave contrasting results: DAVIES et al. [23] showed, in 157 firefighters, that urinary DES excretion did not correlate with lung function, smoking status or lifetime cigarette consumption. Conversely, HAREL et al. [24] demonstrated that 11 smokers with COPD and/or lung infection excreted more urinary DES than 23 never-smokers. The relationships between urinary DES, smoking habits and airflow limitation were extensively addressed by STONE et al. [25]. Using the isotopedilution HPLC method, they demonstrated that smokers with normal lung function $(n=13)$ and COPD patients $(n=21 ; 13$ former and 8 current smokers) excreted more DES than healthy lifetime nonsmokers $(n=22$; mean \pm SD urinary DES $11.0 \pm 4.2$, $11.8 \pm 5.1$ and $7.5 \pm 1.4 \mu$ g per $g$ creatinine, respectively; $\mathrm{p}<0.05$ ) [25]. Interestingly, the authors found that current smoking and the presence of COPD were independently associated with higher urinary DES. Current smokers with COPD excreted $14.3 \pm 4.9 \mu \mathrm{g}$ per $\mathrm{g}$ creatinine in urine, whereas former smokers with COPD excreted $10.2 \pm 4.8 \mu \mathrm{g}$ per $\mathrm{g}$ creatinine [25]. This suggests that smoking cessation may be associated with a reduction of elastin degradation once COPD is clinically established, but not with its complete resolution.

A further study addressed the relationships between smoking, decline of lung function and excess elastin degradation, assessing results of spirometry performed over a period of $12 \mathrm{yrs}$ in the Normative Aging Study [26]. The authors demonstrated that 10 smokers with rapid lung function decline (mean \pm SD forced expiratory volume in one second (FEV1) $91 \pm 27 \mathrm{~mL} \cdot \mathrm{yr}^{-1}$ ) excreted more DES in urine than eight smokers with slow lung function decline (FEV1 $7 \pm 25 \mathrm{~mL} \cdot \mathrm{yr}^{-1} ; \mathrm{p}<0.01$ ). In all subjects, the rate of FEV1 decline was significantly correlated with DES excretion. Both these studies corroborated the hypothesis that COPD occurs because of degradation of lung elastin, most likely due to unopposed elastase activity. In addition, the demonstration that increased elastin degradation occurs in rapid decliners compared with slow decliners offers the prospect that urinary DES could serve as a biological marker for therapies aimed at slowing the progression of COPD. 
The difference in urinary DES between healthy nonsmokers, smokers with normal lung function and COPD patients was confirmed by a study performed in Italy, using the HPCE separation method [18]. This cross-sectional study also dealt with an additional COPD study group, subjects with acute exacerbations of COPD. The two groups did not differ in terms of mean age, smoking history and body mass index. The pulmonary function indices were lower in exacerbating COPD patients. The latter excreted more urinary DES than the stable COPD subjects (mean \pm SD $17.15 \pm 3.42$ and $14.17 \pm 2.33 \mu \mathrm{g}$ per $\mathrm{g}$ creatinine, respectively; $\mathrm{p}<0.05)$. The study failed to demonstrate a relationship between DES excretion and FEV1, and showed that in a 3-day longitudinal study, the coefficient of variation of the daily excretion of DES was $<5 \%$ in four out of five stable COPD patients. However, in a recent study performed by HPLC (in which the correction was provided by spiked samples), it has been demonstrated that adults with COPD showed a high degree of urinary DES variability over a 2-week period, suggesting that the elastase burden to the lungs is not constant [27].

Fewer data exist on urinary DES in subjects with pulmonary emphysema associated with $\alpha_{1}$-antitrypsin deficiency (AATD). Early work, in which urinary DES was detected by RIA [12], compared a group of both children and adults (the latter with or without emphysema) who had AATD (PI*ZZ genotype) with appropriate controls. Urinary DES in children (mean age $10 \mathrm{yrs}$ ) was significantly higher than it was in all adults (mean \pm SD $3.50 \pm 0.62$ versus $2.32 \pm 0.82 \mu \mathrm{g}$ per $100 \mathrm{mg}$ creatinine, respectively; $\mathrm{p}<0.001$ ), but levels in children with AATD were not different from those of age-matched controls [28]. The mean urinary excretion of DES in $17 \mathrm{PI}^{*} \mathrm{ZZ}$ subjects with emphysema (mean FEV1 28\% predicted) was not different from that of six PI*ZZ subjects without emphysema (FEV1 98\% pred) and of normal $(n=26)$ and sarcoid $(n=16)$ subjects.

However, using the HPCE separation method [18], nine PI*ZZ subjects with emphysema (FEV1 29\% pred) had a mean urinary DES significantly higher than that of healthy smokers and nonsmokers, but also higher than that in stable $(\mathrm{p}<0.001)$ or exacerbated $(\mathrm{p}<0.01)$ COPD without AATD [17]. Urinary DES excretion in these PI*ZZ subjects was not different from that found in patients with diffuse bronchiectasis $(n=13)$ and in adults with cystic fibrosis $(n=11$; mean \pm SD $22.3 \pm 7.7,23.3 \pm 2$ and $23.3 \pm 2 \mu \mathrm{g}$ per $\mathrm{g}$ creatinine, respectively). Patients with AATD excreted higher levels of DES in their urine; this was further confirmed by baseline data obtained in clinical trials of augmentation therapy with $\alpha_{1}$-antitrypsin $\left(\alpha_{1}\right.$-AT; discussed hereunder).

In conclusion, these data, with some exceptions, support the concept that, when urine DES is quantified by more accurate separation methods, differences exist among varying groups of subjects, according to the following gradations: healthy nonsmokers $<$ smokers with normal lung function $<$ stable COPD without AATD $<$ exacerbated COPD without AATD $<$ stable COPD with AATD.

\section{URINARY DES AS A SURROGATE END-POINT IN} CLINICAL TRIALS IN COPD SUBJECTS WITHOUT AATD

The first two studies dealing with the effects of drugs on biochemical markers of lung destruction in vivo were published in 1990 and 1991 by the late COHEN and co-workers [29, 30]. The same authors screened, in vitro, a series of drugs belonging to different classes for their ability to affect neutrophil function [31]. Among others, colchicine was shown to inhibit the formylmethionyl-leucyl-phenylalanine-induced secretion of two neutrophil enzymes, myeloperoxidase and D-glucuronidase; therefore, it was selected for a clinical trial in subjects affected by presumed neutrophil-related disease, such as emphysema. The authors enrolled two series of subjects in a double-blind, placebocontrolled study of current or former cigarette smokers with mild emphysema (mean FEV1 51-70\% pred). Randomly selected patients were administered $0.6 \mathrm{mg}$ colchicine orally every $8 \mathrm{~h}$ for 14 days. Before and after treatment, patients were evaluated by bronchoalveolar lavage (BAL) cell counts, BAL fluid neutrophil elastase concentration, plasma elastin peptides, elastase-generated fibrinopeptides and urinary DES (RIA method). When either group was compared with placebo-treated subjects, colchicine therapy did not induce a difference in BAL neutrophils, plasma elastin peptides, fibrinopeptides or urinary DES $[29,30]$. The one parameter affected was the BAL neutrophil elastase, which was significantly reduced after colchicine therapy in eight former smokers compared with eight placebotreated patients [30]. The authors suggested that failure of colchicine to modify elastin peptides or urinary DES may have been due to a slow rate of change of elastin turnover and too short a treatment period in a small sample size.

A few years later, a similar study design was applied to a trial dealing with an oral synthetic elastase inhibitor [32]. MR889 is a cyclic thionic, reversible, slow-binding, competitive serine proteinase inhibitor specific for neutrophil elastase [33]. The aforementioned trial was the first (and remains the only, to the current authors' knowledge) attempt to test a synthetic elastase inhibitor in a clinical trial. In total, 30 stable COPD subjects with mild to moderate emphysema were randomised to receive either MR889 orally $500 \mathrm{mg}$ b.i.d. or placebo for 4 weeks. Plasma elastin peptides and urine DES (RIA method) were evaluated before and after treatment. The study did not identify any change between the two groups in the level of lung destruction parameters after treatment. However, since analysis of individual levels of urine DES showed in some cases a consistent drop, data have been analysed in relation to disease characteristics. When patients were subdivided by duration of disease, MR889treated subjects with more recent onset of symptoms $(<13.3 \mathrm{yrs}$ in this series), showed a significant decrease of urinary DES after treatment $(p<0.004)$, compared with that in MR889-treated patients with a longer duration of symptoms or in the two subgroups of placebo-treated subjects [32]. The baseline FEV1 of the two subgroups with shorter duration disease was slightly, but not significantly, better than that of the two subsets with longer disease. The four groups did not differ in terms of mean age or smoking history. The significance of this finding is uncertain, especially because of the post hoc analysis. The results may signify that, in earlier phases of COPD progression, neutrophil elastase may induce a greater turnover of elastin, making a therapeutic inhibitor more effective.

\section{URINARY DES AS A SURROGATE END-POINT IN CLINICAL TRIALS IN COPD SUBJECTS WITH AATD}

A plasma-purified preparation of human $\alpha_{1}$-AT has been available since 1987 for supplementation therapy in AATD 
subjects, based on evidence that this restored protective $\alpha_{1}$-AT levels in blood and lung epithelial fluid [34]. However, lack of definitive evidence that $\alpha_{1}$-AT supplementation therapy was therapeutically effective prompted STONE et al. [35] to test whether $\alpha_{1}$-AT supplementation reduced urinary DES excretion. Two PI*ZZ subjects (a 63-yr-old female with FEV1 72\% pred and a 41-yr-old male with FEV1 $45 \%$ pred) received monthly infusions of $260 \mathrm{mg} \cdot \mathrm{kg}^{-1} \alpha_{1}$-AT and were followed for 18 months [35]. Urine specimens were collected throughout this period. Means of post-treatment urinary DES values (determined by the isotope-dilution HPLC method) showed a sustained drop of more than $35 \%$ in both subjects from pretreatment values. Interestingly, the female patient had pretreatment urinary DES values much higher than that of the male (19.7 and $10.8 \mu \mathrm{g}$ per g creatinine, respectively; normal value $7.5 \pm 0.3)$. She had better lung function, saccular bronchiectasis and chronically purulent sputum. The study by STONE et al. [35] suggests that $\alpha_{1}$-AT supplementation may prevent elastin degradation in AATD subjects with lung disease.

Based on these prior results, a study was performed to investigate the effects of short-term supplementation therapy on urinary DES in AATD subjects at the Pulmonary Center in Boston (MA, USA) in collaboration with the Italian Registry for Severe AATD [36]. This trial was unblinded and open label. In total, 12 AATD subjects (eight men, four women; 11 PI*ZZ, one $\mathrm{PI}^{*}$ Mprocida/Mprocida) with severe to moderate emphysema (baseline FEV1 $41 \pm 19 \%$ pred), were administered $\alpha_{1}$-AT supplementation with Prolastin ${ }_{\circledast}$ (Bayer Corp., Pittsburgh, PA, USA) with a weekly regimen of $60 \mathrm{mg} \cdot \mathrm{kg}^{-1}$ for 4 weeks. Spot urine specimens were collected for each subject weekly during the 4-week run-in and then prior to each of the four weekly infusions (at the nadir of $\alpha_{1}$-AT plasma levels; "trough specimens"). Further specimens were obtained 2 days after the infusion on weeks 2 and 4 ("peak specimens"). Urinary DES values were determined by the isotope-dilution HPLC method. It was confirmed that AATD subjects with emphysema never receiving $\alpha_{1}$-AT supplementation excreted more urinary DES than healthy smokers (mean \pm SD $13 \pm 5$ versus $7.5 \pm 1.4 \mu \mathrm{g}$ per $\mathrm{g}$ creatinine; values $73 \%$ higher) [36], and that these values were slightly higher than those of COPD subjects with similar degrees of lung function impairment [24]. During the supplementation, the urinary DES excretion was unchanged in comparison with the run-in values $(13 \pm 5.9 \mu \mathrm{g}$ per $\mathrm{g}$ creatinine). Interestingly, comparison of the mean of the two peak specimen values with the mean of the preceding trough specimen values showed a difference of borderline statistical significance $(11.8 \pm 4.4$ and $13.2 \pm 6.6 \mu \mathrm{g}$ per $g$ creatinine, respectively; $\mathrm{p}=0.06)$.

In 2002, STOLLER et al. [37] reported a randomised controlled trial in 26 AATD subjects to evaluate the bioequivalence of two commercially available preparations of pooled human plasma $\alpha_{1}$-AT. The study lasted 24 weeks, and urinary DES excretion was measured weekly by two methods simultaneously, the isotope-dilution HPLC method [15] and RIA [12]. DES values showed a good correlation between the two methods of measurement but no significant differences occurred between values at entry and after 24 weeks of treatment. The data suggested a slow and persistent decrease of urinary DES excretion that was not statistically significant.
Taken together, these results of clinical trials using DES as a marker for elastin breakdown in pulmonary emphysema, with and without AATD, proved negative. However, it is likely that these negative results are reflecting the failure of these study agents or of study designs to reduce elastin degradation, rather than the inability of urinary DES to reflect such change.

\section{RECENT ADVANCES IN DES DETECTION TECHNOLOGY: DES DETERMINATION ON BODY FLUIDS OTHER THAN URINE}

While the interest in DES as an end-point in clinical trials diminished, further research addressed technological advances. MA et al. [19] have developed an analytical method using HPLC followed by electrospray ionisation mass spectrometry (LC-ESI/MS). The LC-ESI/MS method measures the content of DES and IDES by their specific molecular ion mass-to-charge ratio $(m / z)$, which is 526 . DES and IDES can be quantified separately by their different chromatographic retention times. The method is highly sensitive and specific, which allows detection of $0.1 \mathrm{ng}$ of DES and IDES in urine and sputum. Using the LC-MS analysis, MA et al. [19] showed that unconjugated free forms of DES and IDES (which were determined without acid hydrolysis of urine) are also present in urine. In another study, MA et al. [38] further applied the analysis to measure DES and IDES in 24-h urine samples from three cohorts: 12 COPD patients with AATD, seven COPD patients without AATD and 13 control subjects. They found no significant difference in total levels of urinary DES and IDES (measured after acid hydrolysis) but showed statistically significant higher levels of free forms of DES and IDES (unconjugated) in both AATD patients and non-AATD COPD patients compared with control subjects (mean \pm SD $5.12 \pm 0.59$, $6.38 \pm 0.47$ and $1.52 \pm 0.53 \mu \mathrm{g}$ per g creatinine, respectively). Results indicate that the higher ratio of unconjugated DES/ IDES to the total DES/IDES in patients (37-50\%) versus the lower ratio in normal subjects $(18-20 \%)$ may be used as a marker for disease. The method was also used to examine the content of DES and IDES in plasma and sputum of the three cohorts. Levels of DES and IDES in the plasma of patients were found to be significantly higher than that of control subjects. AATD patients $\left(\mathrm{n}=12,1.40 \pm 0.33 \mathrm{ng} \cdot \mathrm{mL}^{-1}\right)$ had higher levels than non-AATD COPD patients $\left(\mathrm{n}=7,0.65 \pm 0.14 \mathrm{ng} \cdot \mathrm{mL}^{-1}\right)$, and the levels in control subjects were much lower $(n=13$, $\left.0.19 \pm 0.02 \mathrm{ng} \cdot \mathrm{mL}^{-1}\right)$. Similarly, the levels of DES and IDES in sputum of AATD patients exceeded the levels in non-AATD COPD patients $\left(1.82 \pm 0.41\right.$ versus $0.55 \pm 0.19 \mathrm{ng} \cdot \mathrm{mL}^{-1}$, respectively), while the levels in the induced sputum samples of normal subjects were below the levels of detection [38].

Further improvement in the LC-MS method has been made by MA et al. [38] using the tandem mass spectrometry (LC-MS/MS) technique, which monitors reaction ions of $m / z 481$ and $m / z 397$ (both ions are produced by collision reaction of molecular ion $m$ / $z 526$ with Argon gas in the LC-MS/MS analysis). This analytical technique further improves the sensitivity (detection limit of $0.01 \mathrm{ng} \cdot \mathrm{mL}^{-1}$ ) and the specificity of the detection: for example, low levels of DES and IDES in plasma or sputum that could not be measured by previous HPLC or LC-MS techniques can be quantified successfully. This higher ratio of free DES/IDES in patients with COPD may reflect increased elastase activity of neutrophils in COPD, as previously shown [39]. 
When urinary DES/IDES were measured simultaneously by mass spectrometry (LC-MS) and ultraviolet absorption (LCUV) methods (most mass spectrometers are also equipped with a UV detector), the UV quantification gave higher and less consistent DES/IDES contents [15] than mass spectrometry $[19,38]$. This suggests that the LC-MS approach, based on the identification of ions with particular mass, is able to detect DES/IDES molecules more specifically. In contrast, the UV method may detect additional substances that absorb at the same wavelength as DES/IDES and that elute within the chromatographic peaks of these latter (figs 3 and 4). In fact, while DES/IDES are the major cross-links, other DES/IDESlike molecules have also been identified in the formation of mature elastin. This may explain the differences between the urinary DES/IDES contents that were higher if determined by LC-UV [15] than by LC-MS [19, 38]. In addition, the lower content of the free form of DES/IDES in urine and total DES/ IDES in sputum and in plasma are only detectable by the more specific and sensitive LC-MS methods. It can be concluded that the highly specific and sensitive LC-MS method more accurately reflects DES/IDES contents in biological fluids.

Using LC-MS or LC-MS/MS analysis could be a method of choice for more specific determination of DES and IDES as reliable biomarkers in biological fluids for the detection of elastin degradation in COPD patients. This analysis has also been successfully used in the detection of DES and IDES in BAL fluid of cigarette smoke-induced mouse models of emphysema [40] and the determination of DES and IDES levels in COPD patients after tiotropium therapy [41]. Importantly, if a method of analysis of a complex biological matrix does not specifically identify DES and IDES, it may detect other molecules produced by elastin degradation that interfere with desmosines [42].

In subsequent work, HPCE methodology underwent advancement, by the combination of the capillary electrophoresis (CE) approach with laser-induced fluorescence (LIF) detection [43]. The method resulted in a significant improvement of sensitivity, allowing detection of amounts of desmosines as low as $5.26 \mu \mathrm{g} \cdot \mathrm{L}^{-1}$ and avoiding pretreatment procedures, such as urine concentration. Although a disadvantage of CE-LIF is that it is unable to discriminate between the two derivatised crosslinks, the results were nevertheless proved reliable and presented as "desmosines" the sum of the two isomers DES and IDES (fig. 5) [43]. Results from urine samples submitted simultaneously to CE-LIF and to CE-UV showed that the former approach reflected more accurate quantification and better recovery of analytes owing to lack of sample preparation, supporting the hypothesis that any sample pretreatment is a disadvantage for the performance of a method [43].

The development of techniques allowing the detection of DES in samples where this cross-link is present in low concentrations made it possible to perform assays in different bodily fluids of interest. In a study dealing with assessment of desmosines by CE-LIF in patients affected by Pseudoxanthoma elasticum (PXE), a rare inheritable disorder characterised by fragmentation and mineralisation of elastic fibres, ANNOVAZZI et al. [44] determined desmosines in plasma. In this simple procedure, $1 \mathrm{~mL}$ of plasma is deproteinised and centrifuged; a $100-\mu \mathrm{L}$ sample is then hydrolysed and derivatised. The mean \pm SD level of desmosines in healthy controls was $55 \pm 3.2 \mu \mathrm{g} \cdot \mathrm{L}^{-1}$, significantly lower than in carriers and subjects affected by PXE.

Plasma (and urine) desmosines content has been determined in a population of 12 patients affected by pulmonary emphysema associated with AATD in a short-term (7-week) longitudinal study during a placebo-controlled trial aimed at evaluating the safety of a single inhalation of hyaluronic acid [45]. This investigation also measured two other biomarkers: elastaseformed fibrinogen fragments (in plasma) and a heparin sulphate epitope, JM403 (in urine). The results demonstrated:

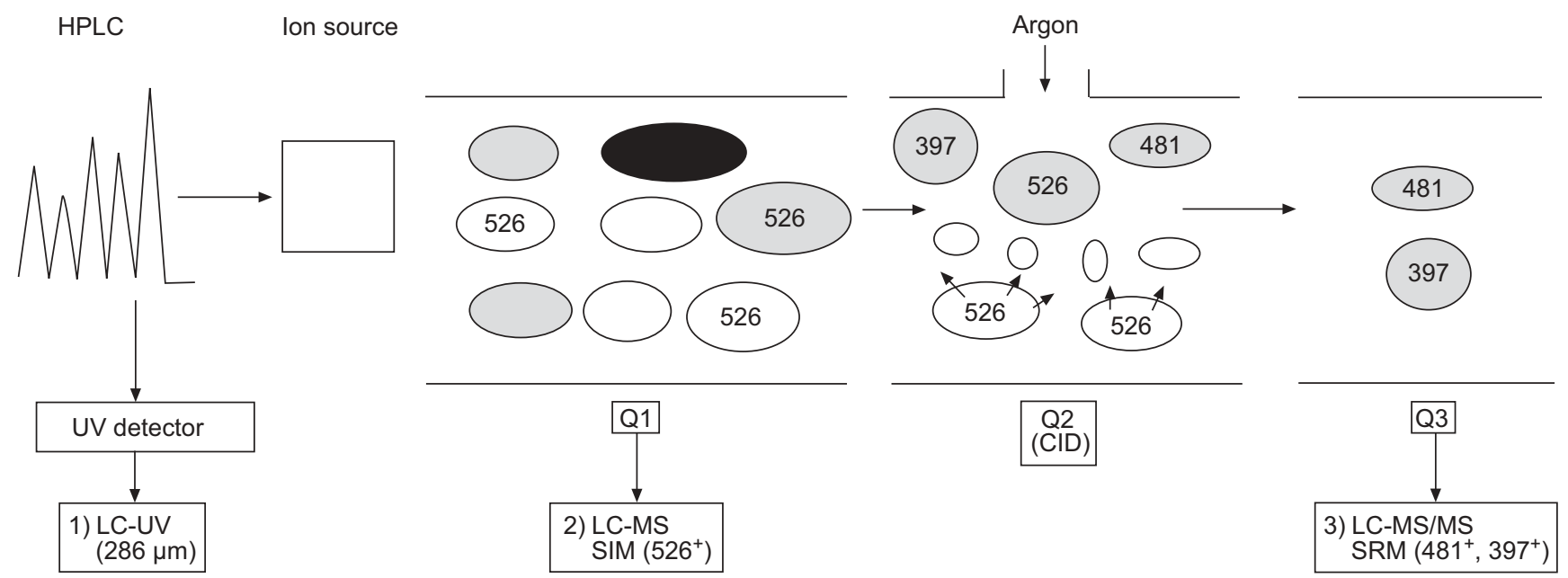

FIGURE 3. Three detection methods for HPLC analysis of desmosine (DES) and isodesmosine (IDES). 1) Liquid chromatography (LC)-ultraviolet (UV): chromatographic peaks after HPLC separation are analysed by a spectrophotometer and measured by the UV absorbance of DES/IDES molecules at $268 \mu \mathrm{m}$. 2) LC-mass spectrometry (MS): chromatographic peaks after HPLC separation are analysed by a mass spectrometer and measured by selected ion monitoring (SIM) of mass-to-charge ratio $(\mathrm{m} / \mathrm{z}) 526$, which represents the two molecular ions of DES/IDES. 3) LC-MS/MS: chromatographic peaks after HPLC separation are analysed by a tandem mass spectrometer and measured by selected reaction monitoring (SRM) of two ions $\mathrm{m} / \mathrm{z} 481$ and $\mathrm{m} / \mathrm{z} 397$, which are two distinctive fragment ions produced by collision-induced dissociation (CID) of the molecular ion ( $\mathrm{m} / \mathrm{z} 526)$ of DES/IDES. Q1, Q2 and Q3: three quadrupoles. 

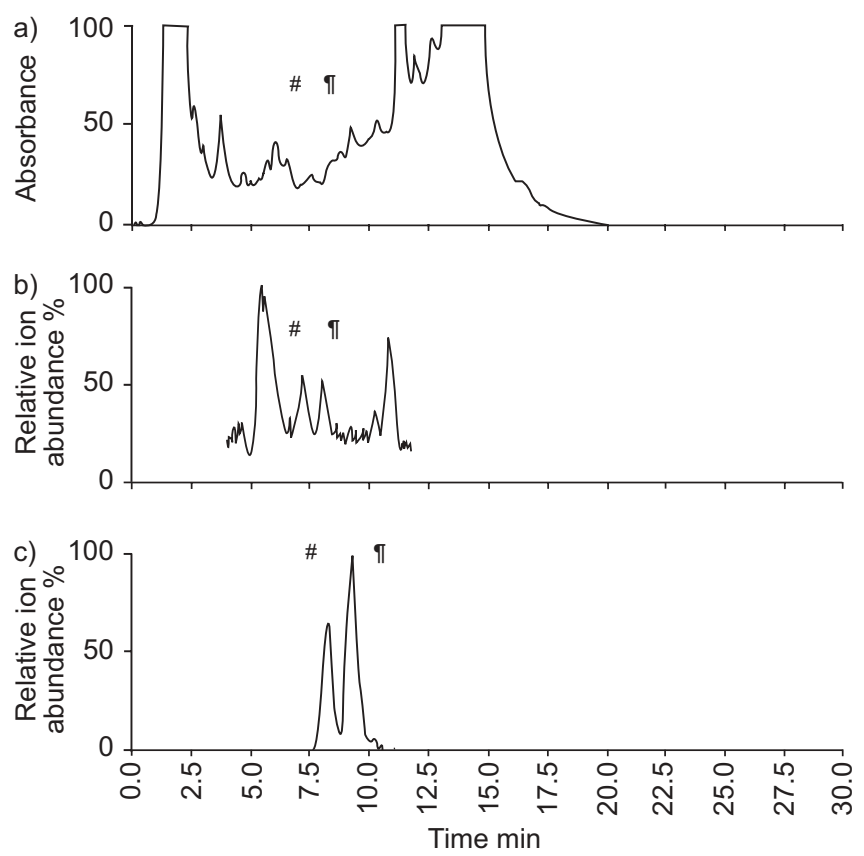

FIGURE 4. Comparison of three analytical methods of desmosine (DES; ${ }^{*}$ ) and isodesmosine (IDES; ") in $0.5 \mathrm{~mL}$ of plasma from a chronic obstructive pulmonary disease patient (containing $0.3 \mathrm{ng}$ of DES and IDES). a) Liquid chromatography (LC)-ultraviolet (UV): HPLC with UV absorbance measurement at $286 \mu \mathrm{m}$. b) LC-mass spectrometry (MS): HPLC with MS. c) LC-MS/MS: HPLC with tandem MS. Significant increases in both specificity and sensitivity are observed from LC-UV to LC-MS and to LC-MS/MS.

1) increased values of plasma desmosines in these patients (median $79 \mu \mathrm{g} \cdot \mathrm{L}^{-1}$ ); 2) a good correlation between plasma and urine desmosines; and 3) good correlations between baseline plasma desmosines values and the transfer coefficient of the lung for carbon monoxide (KCO; $\mathrm{r}=0.81 ; \mathrm{p}<0.01)$, and between urine desmosines and $\mathrm{KCO}(\mathrm{r}=0.65 ; \mathrm{p}<0.05)$. Interestingly, no correlation of desmosines values, either in plasma or in urine, was found with baseline FEV1 values, or with the two other biomarkers.

Determination of desmosines in induced sputum was included in a study that evaluated a series of biomarkers putatively aimed at differentiating COPD subjects with $(n=11)$ and without $(n=15)$ CT-diagnosed emphysema [46]. Although no significant differences were found between the two groups, there was a trend for COPD subjects with emphysema to have more desmosines (assessed by CE-LIF) in induced sputum than COPD subjects without emphysema (median (interquartile range): 12.21 (7.9-13.12) versus 6.31 (5.79-13.03) ng per mg protein). In the latter study, the levels of desmosines in urine and plasma showed the same trend between the two COPD subsets (55.82 versus $38.66 \mu \mathrm{g}$ per g creatinine, and 40.03 versus $29.45 \mathrm{ng} \cdot \mathrm{mL}^{-1}$, respectively).

Improved techniques for determining DES by LC-MS have also made possible analysis in fluids previously prohibited by small amounts. In their study dealing with LC-ESI/MS, MA et al. [19] analysed induced sputum from five COPD patients. The mean DES values were $0.9 \mathrm{ng}$ per $\mathrm{mg}$ protein, and the mean IDES values were $0.6 \mathrm{ng}$ per $\mathrm{mg}$ protein.

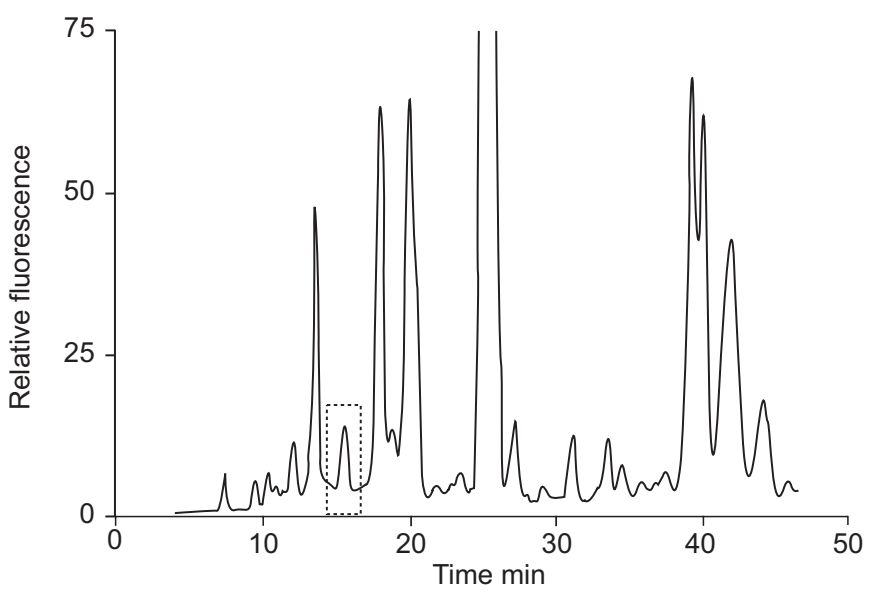

FIGURE 5. Electropherogram showing the peak (in box) of the fluorescein isothiocyanate (FITC)-desmosine/isodesmosine isomers obtained by submitting a urine sample after derivatisation with FITC to micellar electrokinetic chromatography.

A summary of relevant results from investigations of DES/ IDES levels in different clinical settings is reported in table 2.

\section{DESMOSINE AND COPD: ESTABLISHED CONCEPTS, UNRESOLVED ISSUES AND FUTURE DIRECTIONS}

The evidence accumulated over the past 15 yrs indicates that patients with COPD, as well as patients with other destructive lung diseases [18], excrete more urinary DES and IDES than healthy subjects or smokers with normal lung function. These results are consistent with the concept that COPD is associated with accelerated turnover of elastin fibres. Although urinary DES excretion is a specific marker of elastin degradation, it is not specific with regard to the elastic tissue of origin. The presence of COPD suggests that the site of the excess elastin degraded is most likely the lung, but the growing evidence that COPD is associated with systemic dysfunctions of other organs [49], such as the cardiovascular system, does not exclude the possibility that other compartments rich in elastin fibres may contribute to DES excretion. In this respect, the detection of DES and IDES in induced sputum $[19,46]$ of COPD patients confirms that a specific site of elastin degradation is the lung. A remote possibility is that DES/IDES may be entering the alveolar and bronchial spaces via the arterial or venous circulation. With regard to this, DES and IDES are undetectable in induced sputum of normal individuals [19].

The high correlation between urinary and plasma desmosines [45] is consistent with the correlation between urinary and plasma elastin peptides previously reported [9], thus suggesting that plasma and urine generally provide comparable estimates of elastin turnover. The correlation of individual values for plasma and urine levels of desmosines performed by STOLK et al. [45] also diminishes the concern, based on previous experimental findings, that the kidney may sequester elastin peptides and release them over an extended period of time [50]: urinary DES excretion would reflect the changes in blood levels of elastin degradation products, although with more variability. The short-term, longitudinal study of STOLK et al. [45] has shown an acceptable variability (intra-individual coefficient of variation $<10 \%$ ), in spite of some events of mild acute exacerbation not requiring hospitalisation. However, 
TABLE 2 Summary of the clinical investigations on desmosine (DES)/isodesmosine (IDES)

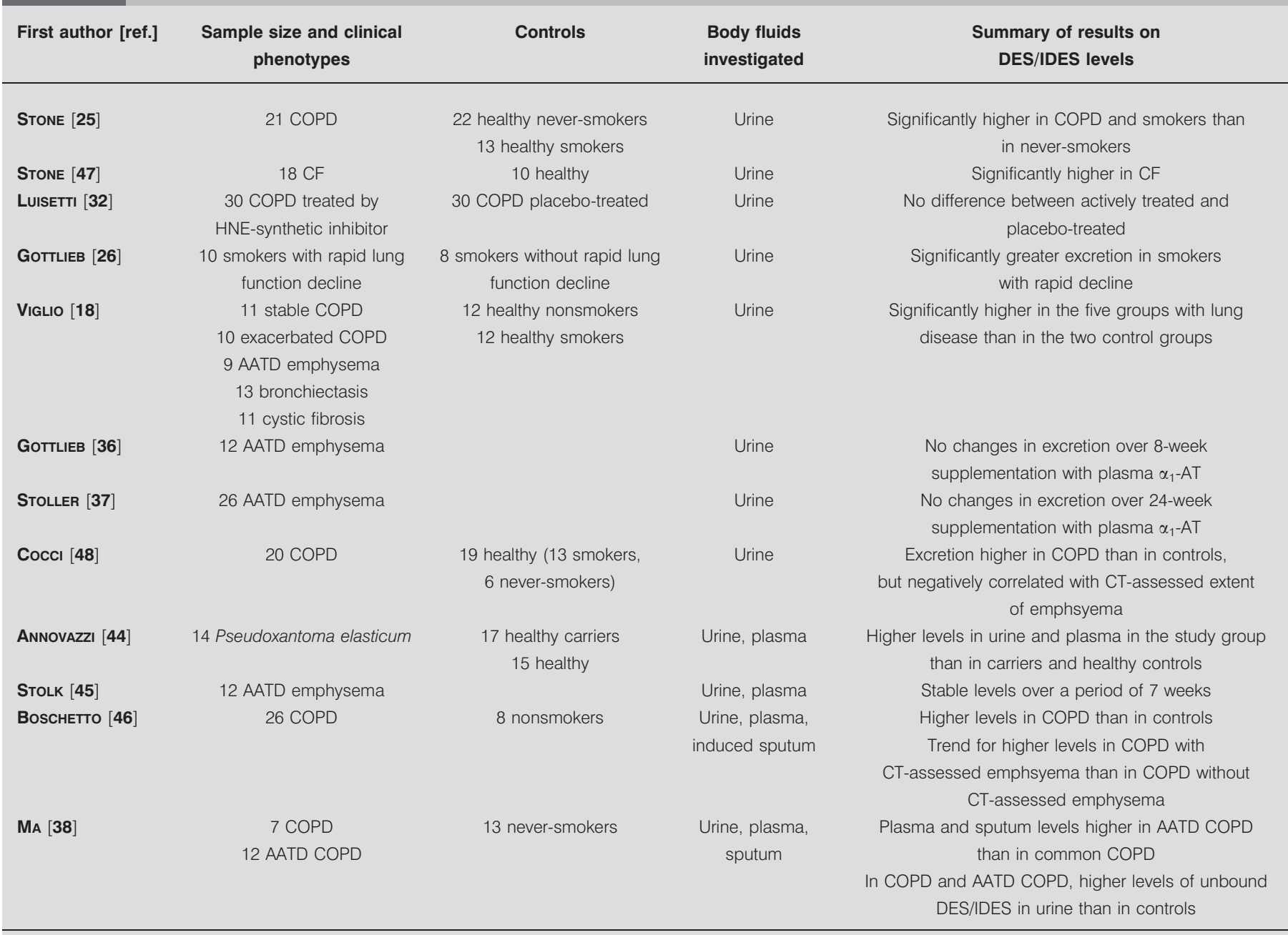

COPD: chronic obstructive pulmonary disease; CF: cystic fibrosis; HNE: human neutrophil elastase; AATD: $\alpha_{1}$-antitrypsin deficiency; $\alpha_{1}$-AT: $\alpha_{1}$-antitrypsin; CT: computed tomography.

there is a preliminary report showing that after severe, acute exacerbations requiring hospitalisation, the recovery period is characterised by a small but significant decrease in urinary DES excretion [51]. Taking into account the previously discussed data on exacerbated COPD $[18,51]$, the impact of exacerbations on DES and IDES remains to be further investigated, using newer, more sensitive and specific analytical techniques.

In summary, urine is still considered the "golden matrix" for assessing DES/IDES levels, although, in this fluid, a correction for creatinine content is needed. Plasma is indeed an interesting matrix, as DES/IDES levels there are lower but also less variable. Sputum DES/IDES levels are of conceptual interest, but of limited usefulness in practice.

A major, as yet unresolved issue, is the relationship between DES and pulmonary function parameters. Attempts to correlate the urinary excretion of DES with FEV1 or an obstruction index (FEV1/forced vital capacity) in cross-sectional studies have been repeatedly fruitless [9, 18, 46]. Longitudinal investigations have been informative. GOTTLIEB et al. [26] found a significant correlation between urinary DES and FEV1 decline in smokers. In a short-term longitudinal study in $\mathrm{PI}^{*} \mathrm{ZZ}$ individuals with emphysema, STOLK et al. [45] could not detect any relationship between plasma or urinary desmosines and FEV1, whereas a significant correlation was found between plasma desmosines $(p<0.01)$ and urinary desmosines $(p<0.05)$ and KCO. In a subsequent investigation of a larger group of patients with emphysema associated with AATD, the lack of significant correlation between urinary desmosines and FEV1 was confirmed, but a significant correlation $(r=0.57, p=0.018)$ between urinary desmosines and phase III of the single-breath nitrogen test was also demonstrated [52].

The possibility exists that FEV1 may not be a parameter specific enough to correlate with elastin [53], since its changes are determined by both airway wall areas and parenchymal attenuation areas, as suggested by CT studies [54]. Conversely, diffusing capacity may be better correlated with 
high-resolution CT quantification of emphysema [55]. In this regard, the correlation between DES and CT assessment of emphysema remains controversial. The Normative Aging Study, in their report on rapid decliners with and without pulmonary emphysema assessed by high-resolution CT, detected no difference in urinary DES excretion between the two groups [26]. There were similar findings in a crosssectional study including COPD subjects with and without CT-assessed emphysema, since neither plasma or urine desmosines correlated with quantitative evaluation of emphysema [46]. However, Cocci et al. [48] showed a reduced urinary excretion of DES in patients with more severe emphysema, suggesting that in advanced emphysematous disease the DES excretion could be related to the reduced lung elastin mass. Overall, physiological parameters of lung function reflect very slowly resolving changes in lung structure, whereas DES and IDES reflect more acute biochemical processes. According to this framework, the preliminary report of a long-term 14month follow-up in 11 AATD individuals with emphysema seemed to support such a concept. In fact, the values of urine desmosines increased significantly after $1 \mathrm{yr}$ compared with baseline $(p=0.027)$, whereas only a trend, with no significance, was observed in the decline of FEV1 and KCO [56].

\section{CONCLUSIONS: IS EVALUATION OF DESMOSINE AND ISODESMOSINE WORTHWHILE AS A BIOCHEMICAL END-POINT IN COPD?}

DES and IDES are unique to elastin, a major component of the lung matrix that undergoes primary damage in emphysema. In this setting, unique products of elastin degradation have excellent potential as a surrogate marker in COPD [57].

COPD is a progressive disease and its natural history spans several decades. The course of the disorder is most appropriately monitored by lung function testing parameters and, more recently, quantitative CT has been proposed for longitudinal studies [58]. An ideal biological surrogate end-point should provide information on the clinical course of the disorder in a relatively short time interval (and at reduced costs), reliably predicting the overall clinical outcome. However, a common misconception is to mistake a correlation with a given clinical outcome for a surrogate end-point [59]. In this context, biochemical markers changing quickly following a therapeutic intervention, such as the decrease in sputum levels of leukotriene $\mathrm{B}_{4}$, interleukin- 8 or neutrophil elastase after a few weeks of supplementation therapy with i.v. $\alpha_{1}$-AT [60], although correlated with the disease's inflammatory processes, cannot be considered a replacement for true clinical outcomes.

DES has been shown to display rather stable levels in biological fluids for several weeks and to resist the effect of mild exacerbations. Now that novel, promising techniques for DES detection are available, circumventing the technical limitations of the past, a study worthy of consideration (or at least nesting in large clinical trials, thus reducing the costs) would involve subjects with carefully defined COPD clinical phenotypes followed for a prolonged period of time by lung function testing, quantitative CT and DES/IDES determinations in biological fluids. From data retrieved from this investigation, some answers may be manifest on the potential usefulness of DES as surrogate end-point in clinical trials.
In conclusion, several observations are worthy of emphasis. 1) Elastin is present in relatively high concentration in the lung and has unique cross-linking amino acids, DES and IDES. In humans, these are present only in elastin and can reflect elastin degradation. 2) Elastin is vulnerable to degradation by both serine elastases and metalloproteases, which occur in neutrophils and macrophages and other cells as part of the inflammatory process in the lung. 3) Elastin peptides in urine are increased in patients with COPD, including those with AATD and COPD. Methodological differences in measuring elastin peptides in urine cause variation in the quantification of elastin peptides, but the quantification usually shows elevations. Recent application of mass spectrometry to measuring DES/IDES directly does not show increases in DES/IDES in urine but shows an increase in the proportion of free DES/ IDES. Free DES/IDES may represent a significant and useful marker in urine. 4) Elastin peptides measured by RIA in plasma have been found to be increased in COPD with and without AATD. Also, specific identification of DES and IDES in plasma shows significant increases, with increases observed for AATD patients exceeding those in patients with COPD with normal levels of $\alpha_{1}$-AT. 5) Use of mass spectrometry has allowed measurement of DES and IDES in sputum, both induced and spontaneously produced. Other analytical methods using CE-LIF have also measured desmosines in induced sputum. The ability to measure DES and IDES in sputum indicates the presence of elastin breakdown in the lung as opposed to in other compartments, such as blood vessels and skin, as a cause of increased elastin components in plasma or urine. 6) Earlier studies indicate the rapid degradative response of amorphous elastin to elastases and the early beginning of elastin resynthesis when degradation has begun $[61,62]$. Such responsiveness should add to the suitability of measuring elastin degradation as an indicator of elastin matrix breakdown and resynthesis. 7) Methodological advances in detecting and quantifying DES/IDES and elastin peptides in plasma, urine and sputum, as well as in BAL, increase the practical usefulness of this parameter for indicating stages of severity in the course of COPD as well as responses to therapy.

Search, assessment and validation of biomarkers and outcome measurements for chronic obstructive pulmonary disease represent very active fields of research [63, 64]. As recently stated by several authors $[65,66]$, an ideal biomarker for chronic obstructive pulmonary disease should be: 1) central to its pathophysiological process; 2) a true surrogate end-point; 3) stable and vary only with events known to be related with chronic obstructive pulmonary disease progression; 4) able to predict progression; 5) cost-effective; and 6) possibly sensitive to intervention factors known to be effective. None of the currently used biomarkers or surrogate markers in chronic obstructive pulmonary disease is able to satisfy all these requisites, including the forced expiratory volume in one second, which shows some limitations [67]. Notwithstanding, methodological progresses, such as those achieved in the proteomic analysis of body fluids or in computed tomography assessment of emphsyema, represent a crucial aspect of validating suitable biomarkers. According to such a framework, the novel analytical techniques developed will result in a better understanding of the possible usefulness of desmosine/isodesmosine in monitoring therapeutic interventions in chronic obstructive pulmonary disease. 


\section{ACKNOWLEDGEMENTS}

The authors' affiliations are as follows. M. Luisetti: Laboratory of Biochemistry and Genetics, Institute of Respiratory Disease, IRCCS San Matteo Hospital Foundation, Pavia, Italy. S. Ma, Y.Y. Lin, G.M. Turino: Dept of Medicine, James P. Mara Center for Lung Disease, St Luke's-Roosevelt Hospital Center, Columbia University College of Physicians and Surgeons, New York, NY, USA. P. Iadarola, S. Viglio: Laboratory of Capillary Electrophoresis, Dept of Biochemistry "A. Castellani", University of Pavia, Pavia, Italy. P.J. Stone: Boston University School of Medicine, Boston, MA, USA. B. Casado: Dept of Bioanalytical Sciences, Nestlé Research Center, Lausanne, Switzerland. G.L. Snider: Dept of Medicine, Boston VA Hospital, Boston, MA, USA.

\section{REFERENCES}

1 Lopez AD, Murray CC. The global burden of disease, 1990-2020. Nat Med 1998; 4: 1241-1243.

2 Chapman KR, Mannino DM, Soriano JB, et al. Epidemiology and costs of chronic obstructive pulmonary disease. Eur Respir J 2006; 27: 188-207.

3 Barnes PJ. Chronic obstructive pulmonary disease. N Engl J Med 2000; 343: 269-280.

4 Anthonisen NR, Connett JE, Kiley JP, et al. Effects of smoking intervention and the use of an inhaled anticholinergic bronchodilator on the rate of decline of FEV1. The Lung Health Study. JAMA 1994; 272: 1497-1505.

5 Cohen AB. Introduction. In: AB Cohen, ed. Pulmonary Emphysema. The Rationale for Therapeutic Intervention. Ann NY Acad Sci 1991; 624S: 1-5.

6 Rosenbloom J, Campbell EJ, Mumford R, et al. Biochemical/ immunologic markers of emphysema. In: AB Cohen, ed. Pulmonary Emphysema. The Rationale for Therapeutic Intervention. Ann NY Acad Sci 1991; 624S: 7-12.

7 Rosenbloom J, Abrams WR, Mecham R. Extracellular matrix 4: the elastic fiber. FASEB J 1993; 7: 1208-1218.

8 Foster JA, Curtiss SW. The regulation of lung elastin synthesis. Am J Physiol 1990; 259: L13-L23.

9 Schriver EE, Davidson JM, Sutcliffe MC, Swindell BB, Bernard GR. Comparison of elastin peptide concentrations in body fluids from healthy volunteers, smokers, and patients with chronic obstructive pulmonary disease. Am Rev Respir Dis 1992; 145: 762-766.

10 Kucich U, Christner P, Lippmann M, et al. Utilization of a peroxidase antiperoxidase complex in an enzyme-linked immunosorbent assay of elastin-derived peptides in human plasma. Am Rev Respir Dis 1985; 131: 709-713.

11 Watanabe $T$, Ishimori $K$, Verplanke AJ, Matsuki $H$, Kasuga H. An enzyme-linked immunosorbent assay (ELISA) for the quantitation of urinary desmosine. Tokai J Exp Clin Med 1989; 14: 347-356.

12 King GS, Mohan VS, Starcher BC. Radioimmunoassay for desmosine. Connect Tissue Res 1980; 7: 263-267.

13 Darnule TV, McKee M, Darnule AT, Turino GM, Mandl I. Solid-phase radioimmunoassay for estimation of elastin peptides in human sera. Anal Biochem 1982; 122: 302-307.

14 Starcher B, Green M, Scott M. Measurement of urinary desmosine as an indicator of acute pulmonary disease. Respiration 1995; 62: 252-257.
15 Stone PJ, Bryan-Rhafdi J, Lucey EC, et al. Measurement of urinary desmosine by isotope dilution and high performance liquid chromatography. Correlation between elastase-induced air-space enlargement in the hamster and elevation of urinary desmosine. Am Rev Respir Dis 1991; 144: 284-290.

16 Stone PJ, Lucey EC, Snider GL, Franzblau C. Effect of diet on urinary excretion of desmosine and hydroxylysyl pyridinoline. Am J Respir Crit Care Med 1994; 149: 174-177.

17 Viglio S, Zanaboni G, Luisetti M, et al. Micellar electrokinetic chromatography for the determination of urinary desmosine and isodesmosine in patients affected by chronic obstructive pulmonary disease. J Chromatogr $B$ Biomed Sci Appl 1998; 714: 87-98.

18 Viglio S, Iadarola P, Lupi A, et al. MEKC of desmosine and isodesmosine in urine of chronic destructive lung disease patients. Eur Respir J 2000; 15: 1039-1045.

19 Ma S, Lieberman S, Turino GM, Lin YY. The detection and quantitation of free desmosine and isodesmosine in human urine and their peptide-bound forms in sputum. Proc Natl Acad Sci USA 2003; 100: 12941-12943.

20 Viglio S, Annovazzi L, Luisetti M, Stolk J, Casado B, Iadarola P. Progress in the methodological strategies for the detection in real samples of desmosine and isodesmosine, two biological markers of elastin degradation. J Sep Sci 2007; 30: 202-213.

21 Goldstein RA, Starcher BC. Urinary excretion of elastin peptides containing desmosine after intratracheal injection of elastase in hamsters. J Clin Invest 1978; 61: 1286-1290.

22 Janoff A, Chanana AD, Joel DD, et al. Evaluation of the urinary desmosine radioimmunoassay as a monitor of lung injury after endobronchial elastase instillation in sheep. Am Rev Respir Dis 1983; 128: 545-551.

23 Davies SF, Offord KP, Brown MG, Campe H, Niewoehner D. Urine desmosine is unrelated to cigarette smoking or to spirometric function. Am Rev Respir Dis 1983; 128: 473-475.

24 Harel S, Janoff A, Yu SY, Hurewitz A, Bergofsky EH. Desmosine radioimmunoassay for measuring elastin degradation in vivo. Am Rev Respir Dis 1980; 122: 769-773.

25 Stone PJ, Gottlieb DJ, O'Connor GT, et al. Elastin and collagen degradation products in urine of smokers with and without chronic obstructive pulmonary disease. Am J Respir Crit Care Med 1995; 151: 952-959.

26 Gottlieb DJ, Stone PJ, Sparrow D, et al. Urinary desmosine excretion in smokers with and without rapid decline of lung function: the Normative Aging Study. Am J Respir Crit Care Med 1996; 154: 1290-1295.

27 Bode DC, Pagani ED, Cumiskey WR, von Roemeling R, Hamel L, Silver PJ. Comparison of urinary desmosine excretion in patients with chronic obstructive pulmonary disease or cystic fibrosis. Pulm Pharmacol Ther 2000; 13: 175-180.

28 Pelham F, Wewers M, Crystal R, Buist AS, Janoff A. Urinary excretion of desmosine (elastin cross-links) in subjects with PiZZ $\alpha_{1}$-antitrypsin deficiency, a phenotype associated with hereditary predisposition to pulmonary emphysema. Am Rev Respir Dis 1985; 132: 821-823.

29 Cohen AB, Girard W, McLarty J, et al. A controlled trial of colchicine to reduce the elastase load in the lungs of cigarette smokers with chronic obstructive pulmonary disease. Am Rev Respir Dis 1990; 142: 63-72. 
30 Cohen AB, Girard W, McLarty J, et al. A controlled trial of colchicine to reduce the elastase load in the lungs of excigarette smokers with chronic obstructive pulmonary disease. Am Rev Respir Dis 1991; 143: 1038-1043.

31 Stevens MD, Miller EJ, Cohen AB. Search for drugs that may reduce the load of neutrophil azurophilic granule enzymes in the lungs of patients with emphysema. Exp Lung Res 1989; 15: 663-680.

32 Luisetti M, Sturani C, Sella D, et al. MR889, a neutrophil elastase inhibitor, in patients with chronic obstructive pulmonary disease: a double-blind, randomized, placebo-controlled clinical trial. Eur Respir J 1996; 9: 1482-1486.

33 Baici A, Pelloso R, Hörler D. The kinetic mechanism of inhibition of human leukocyte elastase by MR889, a new cyclic thiolic compound. Biochem Pharmacol 1990; 39: 919-924.

34 Wewers MD, Casolaro MA, Sellers SE, et al. Replacement therapy for $\alpha_{1}$-antitrypsin deficiency associated with emphysema. N Engl J Med 1987; 316: 1055-1062.

35 Stone PJ, Morris TA 3rd, Franzblau C, Snider GL. Preliminary evidence that augmentation therapy diminishes degradation of cross-linked elastin in $\alpha_{1}$ antitrypsin-deficient humans. Respiration 1995; 62: 76-79.

36 Gottlieb DJ, Luisetti M, Stone PJ, et al. Short-term supplementation therapy does not affect elastin degradation in severe $\alpha_{1}$-antitrypsin deficiency. The AmericanItalian AATD Study Group. Am J Respir Crit Care Med 2000; 162: 2069-2072.

37 Stoller JK, Rouhani F, Brantly M, et al. Biochemical efficacy and safety of a new pooled human plasma $\alpha_{1}$-antitrypsin, Respitin. Chest 2002; 122: 66-74.

38 Ma S, Lin YY, Turino GM. Measurement of desmosine and isodesmosine by mass spectrometry in COPD. Chest 2007; 131: 1363-1371.

39 Rodriguez JR, Seals JE, Radin A, Lin JS, Mandl I, Turino GM. Neutrophil lysosomal elastase activity in normal subjects and in patients with chronic obstructive pulmonary disease. Am Rev Respir Dis 1979; 119: 409-417.

40 Cantor JO, Cerreta JM, Ochoa M, et al. Aerosolized hyaluronan limits airspace enlargement in a mouse model of cigarette smoke-induced pulmonary emphysema. Exp Lung Res 2005; 31: 417-430.

41 Ma S, Lin YY, Turino GM. The effect of tiotropium (TIO) on levels of desmosine and isodesmosine (D/I) in urine, plasma, and sputum in COPD. Eur Respir J 2007; 30: Suppl. 51, 355s.

42 Akagawa M, Suyama K. Mechanism of formation of elastin crosslinks. Connect Tissue Res 2000; 41: 131-141.

43 Annovazzi L, Viglio S, Perani E, et al. Capillary electrophoresis with laser-induced fluorescence detection as a novel sensitive approach for the analysis of desmosines in real samples. Electrophoresis 2004; 25: 683-691.

44 Annovazzi L, Viglio S, Gheduzzi D, et al. High levels of desmosines in urine and plasma of patients with Pseudoxanthoma elasticum. Eur J Clin Invest 2004; 34: 156-164.

45 Stolk J, Veldhuisen B, Annovazzi L, et al. Short-term variability of biomarkers of proteinase activity in patients with emphysema associated with type $Z \alpha_{1}$-antitrypsin deficiency. Respir Res 2005; 6: 47.

46 Boschetto P, Quintavalle S, Zeni E, et al. Association between markers of emphysema and more severe chronic obstructive pulmonary disease. Thorax 2006; 61: 1037-1042.

47 Stone PJ, Konstan MW, Berger M, Dorkin HL, Franzblau C, Snider GL. Elastin and collagen degradation products in urine of patients with cystic fibrosis. Am J Respir Crit Care Med 1995; 152: 157-162.

48 Cocci F, Miniati M, Monti S, et al. Urinary desmosine excretion is inversely correlated with the extent of emphysema in patients with chronic obstructive pulmonary disease. Int J Biochem Cell Biol 2002; 34: 594-604.

49 Agusti AG. Systemic effects of chronic obstructive pulmonary disease. Proc Am Thorac Soc 2005; 2: 367-370.

50 Starcher B, Peterson B. The kinetics of elastolysis: elastin catabolism during experimentally induced fibrosis. Exp Lung Res 1999; 25: 407-424.

51 Fiorenza D, Viglio S, Lupi A, et al. Urinary desmosine excretion in acute exacerbations of COPD: preliminary report. Respir Med 2002; 96: 110-114.

52 Fregonese L, Ferrari F, Fumagalli M, et al. Ventilation inhomogeneity is correlated with biomarkers of parenchymal destruction in $\alpha_{1}$-antitrypsin deficiency. Eur Respir J 2007; 30: Suppl. 51, 620s.

53 Gelb AF, Hogg JC, Müller NL, et al. Contribution of emphsyema and small airways in COPD. Chest 1996; 109: 353-359.

54 Nakano Y, Muro S, Sakai H, et al. Computed tomographic measurements of airway dimensions and emphysema in smokers. Correlation with lung function. Am J Respir Crit Care Med 2000; 162: 1102-1108.

55 Baldi S, Miniati M, Bellina CR, et al. Relationship between extent of pulmonary emphysema by high-resolution computed tomography and lung elastic recoil in patients with chronic obstructive pulmonary disease. Am J Respir Crit Care Med 2001; 164: 585-589.

56 Fregonese L, Fumagalli M, Ferrari F, Luisetti M, Iadarola P, Stolk J. Long-term changes of elastin breakdown products in $\alpha_{1}$-antitrypsin deficiency. Eur Respir J 2007; 30: Suppl. 51, 140 s.

57 MacNee W. Pathogenesis of chronic obstructive pulmonary disease. Proc Am Thorac Soc 2005; 2: 258-266.

58 Newell JD Jr, Hogg JC, Snider GL. Report of a workshop: quantitative computed tomography scanning in longitudinal studies of emphysema. Eur Respir J 2004; 23: 769-775.

59 Fleming TR, DeMets DL. Surrogate end points in clinical trials: are we being misled? Ann Intern Med 1996; 125: 605-613.

60 Stockley RA, Bayley DL, Unsal I, Dowson LJ. The effect of augmentation therapy on bronchial inflammation in $\alpha_{1}$-antitrypsin deficiency. Am J Respir Crit Care Med 2002; 165: 1494-1498.

61 Osman M, Keller S, Hosannah Y, Cantor JO, Turino GM, Mandl I. Impairment of elastin resynthesis in the lungs of hamsters with experimental emphysema induced by sequential administration of elastase and trypsin. J Lab Clin Med 1985; 105: 254-258.

62 Osman M, Kaldany RR, Cantor JO, Turino GM, Mandl I. Stimulation of lung lysyl oxidase activity in hamsters with 
elastase-induced emphysema. Am Rev Respir Dis 1985; 131: 169-170.

63 Barnes PJ, Chowdhury B, Kharitonov SA, et al. Pulmonary biomarkers in chronic obstructive pulmonary disease. Am J Respir Crit Care Med 2006; 174: 6-14.

64 Vestbo J, Anderson W, Coxson HO, et al. Evaluation of COPD Longitudinally to Identify Predictive Surrogate End-points (ECLIPSE). Eur Respir J 2008; 31: 869-873.
65 Jones PW, Agusti AG. Outcomes and markers in the assessment of chronic obstructive pulmonary disease. Eur Respir J 2006; 27: 822-832.

66 Stockley RA. Biomarkers in COPD: time for a deep breath. Thorax 2007; 62: 657-660.

67 Cazzola M, MacNee W, Martinez FJ, et al. Outcomes for COPD pharmacological trials: from lung function to biomarkers. Eur Respir J 2008; 31: 416-469. 